\title{
International R\&D Tournaments and Industrial Policy
}

\author{
Haiwen Zhou \\ Old Dominion University
}

\begin{abstract}
This paper provides a unified approach to study the influence of uncertainty and spillovers on the direction of $R \& D$ policy when firms engage in international $R \& D$ competition. When the reward to the winner is exogenously given, it is shown that whether a government will tax or subsidize its firm is sensitive to the type of uncertainty that characterizes the $R \& D$ process. When the reward to the winner is endogenously determined by $R \& D$ spending, the direction of optimal policy is not only sensitive to the type of uncertainty, but also sensitive to the degree of spillovers.
\end{abstract}

- JEL classification: F12, F13

- Keywords: International R\&D tournaments, Industrial policy, Uncertainty, Spillovers

\section{Introduction}

Two key features of R\&D are uncertainty and spillovers. Uncertainty in R\&D has been well recognized in the literature. Examples include Bagwell and Staiger (1992, 1994). In their empirical study, Coe and Helpman (1995), Keller (2004), and Park (2004) found that international R\&D spillovers were significant. In this paper, a unified approach is provided to study the influence of uncertainty and spillovers on $R \& D$ policy when firms engage in international $R \& D$ competition. We show that both uncertainty and spillovers are important in affecting the

\footnotetext{
*Corresponding address: Haiwen Zhou, Department of Economics Old Dominion University Norfolk, VA 23529, USA. Phone: (757) 683-5785, E-mail: hzhou@odu.edu. 
direction of optimal policy. In this paper, domestic firms compete with foreign firms in product innovation. Governments make policy announcements before firms choose their R\&D spending. A firm's R\&D output is affected by uncertainty and the spillovers from its rivals. When the reward to the winner of the $R \& D$ competition is exogenously given, optimal policy is sensitive to the type of uncertainty that characterizes the R\&D process. Depending on the type of uncertainty, the optimal policy can be subsidizing its firm, laissez-faire, or taxing its firm. The reason behind the above result is that different types of uncertainties lead to different types of reaction functions. Depending on the form of uncertainty, the foreign firm's R\&D spending may decrease, remain the same, or increase with an increase in the domestic firm's R\&D spending. As a result, the optimal policy depends on the form of uncertainty.

When the reward to the winner of $R \& D$ competition is endogenously determined by $R \& D$ spending, the direction of optimal policy is shown to be sensitive to the degree of spillovers. The intuition is the following. Optimal policy depends on whether an increase in the foreign firm's R\&D spending decreases or increases the domestic firm's expected profit. An increase in the foreign firm's R\&D spending has two effects on the domestic firm's expected profit. First, it decreases the domestic firm's probability of winning. This effect decreases the domestic firm's expected profit. Second, the total amount of spillovers to the domestic firm increases and the domestic firm's R\&D output increases. Since the reward to the winner is its $R \& D$ output, an increase in the foreign firm's $R \& D$ spending increases the domestic firm's reward if the domestic firm wins. The latter effect increases the domestic firm's expected profit. When the degree of spillovers is small, the first effect dominates and an increase in the foreign firm's R\&D spending decreases the domestic firm's expected profit. When the degree of spillovers is large, the second effect dominates and an increase in the foreign firm's R\&D increases the domestic firm's expected profit. Thus, optimal policy when the degree of spillovers is small may be opposite to the optimal policy when the degree of spillovers is large.

In a seminal paper, Spencer and Brander (1983) studied the situation that a domestic firm engaged in Cournot competition with a foreign firm. They showed that the domestic government could increase national welfare by announcing a subsidy plan for the domestic firm before firms chose their R\&D spending. ${ }^{1}$ While

\footnotetext{
${ }^{1}$ See Brander (1995) for a survey of the literature on strategic trade theory.
} 
Spencer and Brander (1983) did not take uncertainty in R\&D into account, Bagwell and Staiger $(1992,1994)$ introduced uncertainty into international R\&D competition. They showed that the optimal policy might be sensitive to whether R\&D spending changed the mean or risk of a firm's production cost. Bagwell and Staiger $(1992,1994)$ did not take spillovers in R\&D into account. In Muniagurria and Singh (1997), Leahy and Neary (1999), and DeCourcy (2005), a firm's R\&D output might be affected by spillovers from its rivals. However, they did not take uncertainty in R\&D into consideration. Miyagiwa and Ohno (1997) studied a model in which the degree of appropriability is measured by the length of patent. There are two differences between their paper and this one. First, they restrict random variables to be exponentially distributed, as in the paten race literature. Second, in their paper, when the patent length is zero (low appropriability), each of the two firms gets a duopoly profit. In this model, even if there is full spillover, the winner of R\&D competition still gets the monopoly profit. Employing the all-pay auction approach, Konard (2000) studied contests between domestic and foreign firms. His paper is different from this model as a firm's effort leads to deterministic outcome in his model.

The balance of the paper is organized as follows. Section 2 sets up the basic model. The domestic government chooses policy optimally in the first stage to maximize domestic national welfare and firms choose R\&D spending in the second stage to maximize expected profit. In Section 3, a symmetric equilibrium where governments choose optimal policies simultaneously is studied. Section 4 studies optimal policy when the reward to the winner is endogenously determined by R\&D spending. Section 5 concludes.

\section{The Model}

There are one domestic firm and one foreign firm. They compete in developing a new product by spending on $R \& D$. It is assumed that the new product will be exported to a third country for consumption. There is neither domestic consumption nor foreign consumption of this good. The game has two stages. In the first stage, the domestic government announces a tax or subsidy rate for the domestic firm's R\&D spending. It is assumed that the domestic government can commit to its tax or subsidy schedule. In the second stage, both the domestic and the foreign firms choose R\&D spending simultaneously. In this section, the foreign government is not active in choosing its tax or subsidy rate. The case that both the 
domestic and foreign governments choose policies simultaneously is studied in Section 3.

A firm's R\&D output is specified as the sum of its own R\&D input, spillover from its rival, and a random effect. The realized R\&D output $q_{i}$ of the domestic firm is defined by the following equation

$$
q_{i}=\mu_{i}+\beta \mu_{i}+\varepsilon_{i}
$$

In equation (1), $\mu_{i}$ denotes the domestic firm's R\&D input and $\mu_{i}$ denotes the foreign firm's R\&D input. The spillover rate $\beta$ is exogenously given and satisfies $0 \leq \beta \leq 1$. The influence of uncertainty is represented by the random variable $\varepsilon_{i}$. This approach of modeling uncertainty is different from Bagwell and Staiger (1992, 1994). In their model, R\&D spending alters the density function of realized production cost. In this model, R\&D spending will shift the entire density function without changing the shape of the density function.

The approach of modeling R\&D output here is related to the literature on labor tournaments and R\&D spillovers. First, without the spillover effect, equation (1) is similar to the formula used in the literature on labor tournaments, see Lazear and Rosen (1981) for an example. Second, without the uncertainty effect, (1) is similar to the literature on R\&D spillovers, see d'Aspremont and Jacquemin (1988) for an example. Zhou (2006) has a more detailed illustration of this R\&D output function.

$R \& D$ tournaments are frequently observed in reality. For example, Super Efficient Refrigerator Program Inc., a coalition of 25 private and public electric utilities, offered 30 million dollars for the developer of a refrigerator that could save energy significantly over current models. Frigidaire Co. and Whirlpool Corp. were selected as the two finalists from 14 contestants to compete for this reward (The Washington Post, December 20, 1992). Whirlpool won this contest. In this example, firms competed to produce the best innovation on a specific date, rather than to discover a new product of a given quality.

Let $\varepsilon_{j}$ denote a random variable. The foreign firm's R\&D output is defined by $q_{j}=\mu_{j}+\beta \mu_{i}+\varepsilon_{j}$. It is assumed that $\varepsilon_{i}$ and $\varepsilon_{j}$ are identically and independently distributed. Let the distribution function of these random variables be denoted by $F$, which is assumed to be continuous and twice differentiable. The corresponding density function is denoted by $f$. The firm that produces the higher output wins the contest. The winner of the competition gets a fixed reward of $W_{1}$ and the loser gets a fixed payoff of $W_{2}, W_{1} \geq W_{2}$. If the winner of the R\&D competition gets perfect 
patent protection for its product, $W_{2}$ may be zero. When patent protection is not perfect, $W_{2}$ may be positive.

The game is solved by backward induction. The second stage is studied first.

\section{A. The Second Stage}

In the second stage, firms engage in $R \& D$ competition. For the domestic firm to win, it must be sure that

$$
\mu_{i}+\beta \mu_{j}+\varepsilon_{i}>\mu_{j}+\beta \mu_{i}+\varepsilon_{j}
$$

The above inequality is equivalent to

$$
(1-\beta)\left(\mu_{i}-\mu_{j}\right)+\varepsilon_{i}>\varepsilon_{j} .
$$

Given the R\&D spending of its rival, the domestic firm's probability of winning the contest is $F\left[(1-\beta)\left(\mu_{i}-\mu_{j}\right)+\varepsilon_{i}\right]$ for a given $\varepsilon_{i}$. Integrating over all possible realization of $\varepsilon_{i}$, the domestic firm's expected probability of winning the contest is $\int_{-\infty}^{+\infty} F\left[(1-\beta)\left(\mu_{i}-\mu_{j}\right)+\varepsilon_{i}\right] f\left(\varepsilon_{i}\right) d \varepsilon_{i}$.

The domestic government may choose a tax or subsidy on the domestic firm's R\&D spending in the first stage. Let the tax or subsidy rate chosen by the domestic government be denoted by $t_{i},-1<t_{i}<1$. When $t_{i}$ is positive (negative), it is a subsidy (tax). Let $C\left(\mu_{i}\right)$ denote the cost function for the domestic firm. It is assumed that C'>0 and C" $>0$. With the tax or subsidy, the domestic firm's net R\&D cost is $\left(1-t_{i}\right) C\left(\mu_{i}\right)$.

The domestic firm's expected profit is

$$
\begin{aligned}
\Pi_{i} & =W_{1} \int_{-\infty}^{+\infty} F\left[(1-\beta)\left(\mu_{i}-\mu_{j}\right)+\varepsilon_{i}\right] f\left(\varepsilon_{i}\right) d \varepsilon_{i} \\
& +W_{2}\left(1-\int_{-\infty}^{+\infty} F\left[(1-\beta)\left(\mu_{i}-\mu_{j}\right)+\varepsilon_{i}\right] f\left(\varepsilon_{i}\right) d \varepsilon_{i}\right)-\left(1-t_{i}\right) C\left(\mu_{i}\right) \\
& =\left(W_{1}-W_{2}\right) \int_{-\infty}^{+\infty} F\left[(1-\beta)\left(\mu_{i}-\mu_{j}\right)+\varepsilon_{i}\right] f\left(\varepsilon_{i}\right) d \varepsilon_{i}+W_{2}-\left(1-t_{i}\right) C\left(\mu_{i}\right) .
\end{aligned}
$$

The domestic firm chooses $\mu_{i}$ to maximize its expected payoff (2). Assuming the existence of an interior solution, the first order condition for profit maximization is

$$
\frac{d \Pi_{i}}{d \mu_{i}}=\left(W_{1}-W_{2}\right)(1-\beta) \int_{-\infty}^{+\infty} f\left[(1-\beta)\left(\mu_{i}-\mu_{j}\right)+\varepsilon_{i}\right] f\left(\varepsilon_{i}\right) d \varepsilon_{i}-\left(1-t_{i}\right) C^{\prime}\left(\mu_{i}\right)=0
$$


It is assumed that the second order condition for the domestic firm's profit maximization is satisfied. ${ }^{2}$

From (3a), the response of the domestic firm to a change of the foreign firm's R\&D spending is given by

$$
\begin{aligned}
\frac{\partial \mu_{i}}{\partial \mu_{j}} & =\frac{-\partial^{2} \Pi_{i} / \partial \mu_{i} \partial \mu_{j}}{\partial^{2} \Pi_{i} / \partial^{2} \mu_{i}} \\
& =\frac{\left(W_{1}-W_{2}\right)(1-\beta) \int_{-\infty}^{+\infty} f^{\prime}\left[(1-\beta)\left(\mu_{i}-\mu_{j}\right)+\varepsilon_{i}\right] f\left(\varepsilon_{i}\right) d \varepsilon_{i}}{\partial^{2} \Pi_{i} / \partial^{2} \mu_{i}}
\end{aligned}
$$

From the second order condition for the domestic firm's profit maximization, $\partial^{2} \Pi_{i} / \partial^{2} \mu_{i}<0$. From (4), the sign of $\partial \mu_{i} / \partial \mu_{j}$ depends on the sign of $f^{\prime}$. When $f^{\prime}>0, \partial \mu_{i} / \partial \mu_{j}<0$ and the reaction function has a negative slope; when $f^{\prime}=0$, $\partial \mu_{i}^{\prime} \partial \mu_{j}=0$ and the reaction function has a slope of zero; when $f^{\prime}<0, \partial \mu_{i} / \partial \mu_{j}>0$, and the reaction function has a positive slope. Using the terminology of Bulow et al. (1985), when $f^{\prime}>0\left(f^{\prime}<0\right)$, the domestic firm and the foreign firm's R\&D spending are strategic substitutes (strategic complements). Similar to their study, whether firms' R\&D spending are strategic substitutes or complements is sensitive to the shape of the density function.

Here the density function is required to be globally monotonic. There are some distribution functions satisfying this requirement. For example, the power function distribution satisfies $f^{\prime}>0$; the uniform distribution satisfies $f^{\prime}=0$; and the exponential distribution satisfies $f^{\prime}<0$. One interpretation of $f$ is that it measures technological opportunities of an industry. A positive density function may indicate an industry rich in technological opportunities and a negative density function may indicate an industry lacking technological opportunities. Levin and Reiss (1988) provided a detailed study about the importance of technological opportunities in affecting firms' R\&D spending.

The foreign firm has the same cost function as the domestic firm. Its expected profit $\Pi_{j}$ is $\left(W_{1}-W_{2}\right) \int_{-\infty}^{+\infty} F\left[(1-\beta)\left(\mu_{j}-\mu_{i}\right)+\varepsilon_{j}\right] f\left(\varepsilon_{j}\right) d \varepsilon_{j}+W_{2}-C\left(\mu_{j}\right)$. The first order condition for the foreign firm's profit maximization is

$$
\left(W_{1}-W_{2}\right)(1-\beta) \int_{-\infty}^{+\infty} f\left[(1-\beta)\left(\mu_{j}-\mu_{i}\right)+\varepsilon_{j}\right] f\left(\varepsilon_{j}\right) d \varepsilon_{j}-C^{\prime}\left(\mu_{j}\right)=0
$$

\footnotetext{
${ }^{2}$ For example, when $W_{1}=1.5, W_{2}=0, k=1, \beta=0$, and $f(\varepsilon)=1$ for $\varepsilon \in[-0.5,0.5]$, the second order condition for profit maximization is satisfied.
} 
It is assumed that the second order condition for the foreign firm's profit maximization is satisfied.

\section{B. The First Stage}

In this subsection, the domestic government's optimal decision in the first stage is studied. Anticipating firms' R\&D spending in the second stage, the domestic government chooses taxes or subsidies optimally in the first stage. The domestic government's objective is to maximize national welfare. It is assumed that the domestic government puts equal weight on the domestic firm's profit and its tax revenue (or subsidy spending). As there is no domestic consumption of the new product, national welfare for the domestic country is

$$
\begin{aligned}
S & =\left(W_{1}-W_{2}\right) \int_{-\infty}^{+\infty} F\left[(1-\beta)\left(\mu_{i}-\mu_{j}\right)+\varepsilon_{i}\right] f d \varepsilon_{i}+W_{2}-\left(1-t_{i}\right) C\left(\mu_{i}\right)-t_{i} C\left(\mu_{i}\right) \\
& =\left(W_{1}-W_{2}\right) \int_{-\infty}^{+\infty} F\left[(1-\beta)\left(\mu_{i}-\mu_{j}\right)+\varepsilon_{i}\right] f d \varepsilon_{i}+W_{2}-C\left(\mu_{i}\right) .
\end{aligned}
$$

The first order condition for domestic social welfare maximization is

$$
\begin{aligned}
\frac{d S}{d t_{i}}=\{ & \left.\left(W_{1}-W_{2}\right)(1-\beta) \int_{-\infty}^{+\infty} f\left[(1-\beta)\left(\mu_{i}-\mu_{j}\right)+\varepsilon_{i}\right] f\left(\varepsilon_{i}\right) d \varepsilon_{i}-C\left(\mu_{i}\right)\right\} \frac{d \mu_{i}}{d t_{i}} \\
& -\left(W_{1}-W_{2}\right)(1-\beta) \int_{-\infty}^{+\infty} f\left[(1-\beta)\left(\mu_{i}-\mu_{j}\right)+\varepsilon_{i}\right] f\left(\varepsilon_{i}\right) d \varepsilon_{i} \frac{d \mu_{j}}{d t_{i}} .
\end{aligned}
$$

From (3a), it can be shown that

$$
\left(W_{1}-W_{2}\right)(1-\beta) \int_{-\infty}^{+\infty} f\left[(1-\beta)\left(\mu_{i}-\mu_{j}\right)+\varepsilon_{i}\right] f\left(\varepsilon_{i}\right) d \varepsilon_{i}=\left(1-t_{i}\right) C^{\prime}\left(\mu_{i}\right) .
$$

Substituting the above equation into (5) yields

$$
\frac{d S}{d t_{i}}=-t_{i} C^{\prime}\left(\mu_{i}\right) \frac{d \mu_{i}}{d t_{i}}-\left(1-t_{i}\right) C^{\prime}\left(\mu_{i}\right) \frac{d \mu_{j}}{d t_{i}}
$$

Setting (6) equal to zero, optimal tax or subsidy rate is given by

$$
\frac{t_{i}}{1-t_{i}}=-\frac{d \mu_{j}}{d t_{i}} / \frac{d \mu_{i}}{d t_{i}}
$$

Total differentiation of (3a) leads to 


$$
\begin{gathered}
{\left[\left(W_{1}-W_{2}\right)(1-\beta)^{2} \int_{-\infty}^{+\infty} f^{\prime}\left[(1-\beta)\left(\mu_{i}-\mu_{j}\right)+\varepsilon_{i}\right] f d \varepsilon_{i}-\left(1-t_{i}\right) C^{\prime \prime}\left(\mu_{i}\right)\right] d \mu_{i}} \\
-\left(W_{1}-W_{2}\right)(1-\beta)^{2} \int_{-\infty}^{+\infty} f^{\prime}\left[(1-\beta)\left(\mu_{i}-\mu_{j}\right)+\varepsilon_{i}\right] f d \varepsilon_{i} d \mu_{i}=-C^{\prime}\left(\mu_{i}\right) d t
\end{gathered}
$$

Total differentiation of (3b) leads to

$$
\begin{aligned}
& -\left(W_{1}-W_{2}\right)(1-\beta)^{2} \int_{-\infty}^{+\infty} f^{\prime}\left[(1-\beta)\left(\mu_{i}-\mu_{j}\right)+\varepsilon_{j}\right] f d \varepsilon_{j} d \mu_{i} \\
& +\left[\left(W_{1}-W_{2}\right)(1-\beta)^{2} \int_{-\infty}^{+\infty} f^{\prime}\left[(1-\beta)\left(\mu_{j}-\mu_{i}\right)+\varepsilon_{j}\right] f d \varepsilon_{j}-C^{\prime \prime}\left(\mu_{j}\right)\right] d \mu_{j}=0 .
\end{aligned}
$$

Let $\Delta$ denote the determinant of the $2 \times 2$ Jacobian matrix of (8). For stability, it is assumed that $\Delta$ is positive. From (8), how $\mu_{i}$ and $\mu_{j}$ change with $t_{i}$ is given by

$$
\begin{aligned}
\frac{d \mu_{i}}{d t_{i}} & =\frac{\left.-C^{\prime}\left(\mu_{i}\right)\left(W_{1}-W_{2}\right)(1-\beta)^{2} \int_{-\infty}^{+\infty} f^{\prime}\left[(1-\beta)\left(\mu_{j}-\mu_{i}\right)+\varepsilon_{j}\right] f d \varepsilon_{j}-C^{\prime \prime}\left(\mu_{j}\right)\right]}{\Delta}, \\
\frac{d \mu_{j}}{d t_{i}} & =\frac{-C^{\prime}\left(\mu_{i}\right)\left(W_{1}-W_{2}\right)(1-\beta)^{2} \int_{-\infty}^{+\infty} f^{\prime}\left[(1-\beta)\left(\mu_{j}-\mu_{i}\right)+\varepsilon_{j}\right] f d \varepsilon_{j}}{\Delta}
\end{aligned}
$$

From (9a), a subsidy (tax) by the domestic government on R\&D spending will increase (decrease) the domestic firm's R\&D spending. Plugging (9) into (7) yields

$$
\frac{t_{i}}{1-t_{i}}=\frac{\left(W_{1}-W_{2}\right)(1-\beta)^{2} \int_{-\infty}^{+\infty} f^{\prime}\left[(1-\beta)\left(\mu_{j}-\mu_{i}\right)+\varepsilon_{j}\right] f d \varepsilon_{j}}{-\left\{\left(W_{1}-W_{2}\right)(1-\beta)^{2} \int_{-\infty}^{+\infty} f^{\prime}\left[(1-\beta)\left(\mu_{j}-\mu_{i}\right)+\varepsilon_{j}\right] f d \varepsilon_{j}-C^{\prime \prime}\left(\mu_{j}\right)\right\}} .
$$

From (10), the optimal tax or subsidy is

$$
t_{i}=\frac{\left(W_{1}-W_{2}\right)(1-\beta)^{2} \int_{-\infty}^{+\infty} f^{\prime}\left[(1-\beta)\left(\mu_{j}-\mu_{i}\right)+\varepsilon_{j}\right] f d \varepsilon_{i}}{C^{\prime \prime}\left(\mu_{j}\right)}
$$

The following proposition shows that optimal R\&D policy is sensitive to the type of uncertainty that characterizes the R\&D process. It shows that the domestic government is more likely to subsidize R\&D spending in an industry richer in technological opportunities.

Proposition 1. When reward to the winner of $R \& D$ competition is exogenously given, a sufficient condition for the domestic government to tax the domestic firm is that $f^{\prime}<0$; a sufficient condition for the domestic government to be laissez-faire is that $f^{\prime}=0$; a sufficient condition for the domestic government to subsidize the domestic firm is that $f^{\prime}>0$. 
Proof: Since $C^{\prime \prime}\left(\mu_{j}\right)>0$, from (11), the sign of $t_{i}$ is the same as the sign of $f^{\prime}$. Q.E.D.

The intuition behind Proposition 1 is the following. In general, the direction of optimal policy depends on the slope of the reaction function. From (4), there are three cases. First, when $f^{\prime}<0$, a decrease in the domestic firm's R\&D spending leads to a decrease in the foreign firm's R\&D spending. As the two firms' $R \& D$ spending are strategic complements, the domestic government's optimal policy is to tax the domestic firm. Second, when $f^{\prime}=0$, a change in the domestic firm's $R \& D$ spending will not change the foreign firm's $R \& D$ spending. As there is no strategic role for the domestic government to play, the optimal policy is laissezfaire. Finally, when $f^{\prime}>0$, an increase in the domestic firm's R\&D spending leads to a decrease in the foreign firm's R\&D spending. As firms' $R \& D$ spending are strategic substitutes, the domestic government's optimal policy is to subsidize the domestic firm.

What is the impact of the domestic government's intervention on the foreign firm's expected profit? Depending on the sign of $f^{\prime}$, there are three possibilities. First, for $f^{\prime}<0$, when the domestic government taxes the domestic firm, the domestic firm's R\&D spending decreases. The foreign firm will also decrease R\&D spending and its expected profit increases. Second, when $f^{\prime}=0$, the foreign firm's expected profit is not affected by domestic government. Finally, for $f^{\prime}>0$, when the domestic government subsidizes the domestic firm, the domestic firm's $R \& D$ spending increases. The foreign firm's $R \& D$ spending decreases and its expected profit decreases.

From (11), it is clear that the optimal subsidy or tax increases with the prize spread $W_{1}-W_{2}$.

\section{Symmetric Equilibrium}

In Section 2, only the domestic government is active in choosing its industrial policy. In this section, the foreign government may also choose its subsidy or tax to the foreign firm to maximize the foreign country's welfare. The Nash equilibrium that the domestic and foreign governments choose taxes or subsidies simultaneously in the first stage is studied. Let the foreign government's tax or subsidy rate to the foreign firm's R\&D spending be denoted by $t_{j}$. A Nash equilibrium in policies is a pair of tax or subsidy rates $\left(t_{i}, t_{j}\right)$ such that $t_{i}$ maximizes the domestic country's welfare, given $t_{j}$. At the same time, $t_{j}$ maximizes the foreign 
country's welfare, given $t_{i}$. In a symmetric equilibrium, governments choose the same level of tax or subsidy rate in the first stage and firms choose the same level of $R \& D$ spending in the second stage.

With the introduction of the foreign tax or subsidy, equation (3a) will not change. Equation ( $3 b$ ) changes to

$$
\left(W_{1}-W_{2}\right)(1-\beta) \int_{-\infty}^{+\infty} f\left[(1-\beta)\left(\mu_{j}-\mu_{i}\right)+\varepsilon_{j}\right] f\left(\varepsilon_{j}\right) d \varepsilon_{j}-\left(1-t_{j}\right) C^{\prime}\left(\mu_{j}\right)=0 .
$$

Equation (10) changes to

$$
\frac{t_{i}}{1-t_{i}}=\frac{\left(W_{1}-W_{2}\right)(1-\beta)^{2} \int_{-\infty}^{+\infty} f^{\prime}\left[(1-\beta)\left(\mu_{j}-\mu_{i}\right)+\varepsilon_{j}\right] f d \varepsilon_{j}}{-\left\{\left(W_{1}-W_{2}\right)(1-\beta)^{2} \int_{-\infty}^{+\infty} f^{\prime}\left[(1-\beta)\left(\mu_{j}-\mu_{i}\right)+\varepsilon_{j}\right] f d \varepsilon_{j}-\left(1-t_{j}\right) C^{\prime \prime}\left(\mu_{j}\right)\right\}} .
$$

In a symmetric equilibrium, $t_{i}=t_{j}=t$ and $\mu_{i}=\mu_{j}$. Thus, the above equation reduces to

$$
\frac{t}{1-t}=\frac{\left(W_{1}-W_{2}\right)(1-\beta)^{2} \int_{-\infty}^{+\infty} f^{\prime} f d \varepsilon_{j}}{-\left\{\left(W_{1}-W_{2}\right)(1-\beta)^{2} \int_{-\infty}^{+\infty} f^{\prime} f d \varepsilon_{j}-(1-t) C^{\prime \prime}\left(\mu_{j}\right)\right\}} .
$$

Let $f_{U}\left(f_{L}\right)$ denote the value of the density function at the least upper bound (the highest lower bound) of its support. The following proposition characterizes optimal policy in a symmetric equilibrium. ${ }^{3}$

Proposition 2. In a symmetric equilibrium, a necessary and sufficient condition for a government to tax its firm is that $f_{U}<f_{L}$; a necessary and sufficient condition

${ }^{3}$ The situation that governments choose reward to their firms optimally to maximize national welfare is similar. Let $W_{i}$ denote the reward chosen by the domestic government for the domestic firm. If the domestic firm loses the R\&D competition, its reward is $W_{2}$. The foreign government may also choose a reward $W_{j}$ simultaneously for the foreign firm. The domestic firm maximizes its expected profit $\left(W_{i}-W_{2}\right)(1-\beta)^{2} \int_{-\infty}^{+\infty} F\left[(1-\beta)\left(\mu_{i}-\mu_{j}\right)+\varepsilon_{i}\right] f\left(\varepsilon_{i}\right) d \varepsilon_{i}+W_{2}-C\left(\mu_{i}\right)$. Equation (10') changes to

$1-\frac{W_{i}-W_{2}}{W_{1}-W_{2}}=\frac{\left(W_{j}-W_{2}\right)(1-\beta)^{2} \int_{-\infty}^{+\infty} f^{\prime}\left(\varepsilon_{j}\right) f d \varepsilon_{j}}{-\left\{\left(W_{j}-W_{2}\right)(1-\beta)^{2} \int_{-\infty}^{+\infty} f^{\prime}\left(\varepsilon_{j}\right) f d \varepsilon_{j}-k\right\}}$. From this equation, whether $1-\frac{W_{i}-W_{2}}{W_{1}-W_{2}}$ is smaller, equal to, or less than 1 depends on the sign of the nominator of the right side of this equation. For $f_{U}<f_{L} ; W_{i}<W_{1}$; for $f_{U}=f_{L}, W_{i}=W_{1} ;$ and for $f_{U}>f_{L} ; W_{i}>W_{1}$. Thus, for a given optimal tax or subsidy rate to $R \& D$ spending, an equivalent optimal reward can be found. For a given optimal reward, an equivalent optimal R\&D tax or subsidy rate can be found. 
for a government to be laissez-faire is that $f_{U}=f_{L}$; a necessary and sufficient condition for a government to subsidize its firm is that $f_{U}>f_{L}$.

Proof: The sign of the left side of (10') is the same as the sign of $t$ since 1- $t$ is always larger than zero. From the second order condition of the foreign firm's profit maximization, the denominator of the right side of (10') is negative. Thus, the sign of the right side of $(10)$ is the same as the sign of $\int_{-\infty}^{+\infty} f^{\prime} f d \varepsilon_{j}$. As a result, the sign of $t_{i}$ is the same as the sign of $\int_{-\infty}^{+\infty} f^{\prime} f d \varepsilon_{j}$. Integrating by parts, it can be shown that $\int_{-\infty}^{+\infty} f^{\prime} f d \varepsilon_{j}=\frac{1}{2}\left(f_{U}^{2}-f_{L}^{2}\right)$. Therefore, $t_{i}>0$ if and only if $f_{U}>f_{L} ; t_{i}=0$ if and only if $f_{U}=f_{L} ; t_{i}<0$ if and only if $f_{U}<f_{L}$.

Q.E.D.

A special case $f_{U}<f_{L}$ of is that $f^{\prime}<0$ globally and $f^{\prime}>0$ is a special case of $f_{U}$ $>f_{L}$. Similarly, $f^{\prime}=0$ globally is a special case of $f_{U}=f_{L}$.

From Proposition 2, when random variables are symmetrically distributed, the optimal R\&D policy is laissez-faire. Some examples of symmetric distribution functions include the normal distribution and the uniform distribution. From Proposition 2, the direction of the optimal policy is unaffected by the possible presence of foreign tax or subsidy. Thus, the domestic government will subsidize or tax the domestic firm's R\&D spending no matter the foreign government subsidizes or taxes the foreign firm or not.

Bagwell and Staiger $(1992,1994)$ and Miyagiwa and Ohno (1997) studied the domestic government's local incentives to tax or subsidize the domestic firm when the initial tax or subsidy rate was zero. Here, the global incentive for the domestic government to tax or subsidize $\mathrm{R} \& \mathrm{D}$ spending is established.

From this point and on, let the cost function take the quadratic form,

$$
C\left(\mu_{i}\right)=\frac{k}{2} \mu_{i}^{2}
$$

where $k$ is a positive constant.

In a symmetric equilibrium, $t_{i}=t_{j}=t$. In addition, $\mu_{i}=\mu_{j}$. From (10') and (12), optimal tax or subsidy rate is given by

$$
\frac{t}{1-t}=\frac{\left(W_{1}-W_{2}\right)(1-\beta)^{2} \int_{-\infty}^{+\infty} f^{\prime} f d \varepsilon}{-\left[\left(W_{1}-W_{2}\right)(1-\beta)^{2} \int_{-\infty}^{+\infty} f^{\prime} f d \varepsilon-(1-t) k\right]}
$$

Equation (13) is equivalent to

$$
t^{2}-t+\frac{\left(W_{1}-W_{2}\right)(1-\beta)^{2} \int_{-\infty}^{+\infty} f^{\prime} f d \varepsilon_{j}}{k}=0 .
$$


Solving (14) for $t$ leads to two roots. The larger root is discarded because it implies that the response from the foreign firm when the domestic country imposes a tax or subsidy on the domestic firm will be larger than the response from the domestic firm. That will not be stable. The smaller root is kept, which is

$$
t=\frac{1-\sqrt{1-\frac{4(1-\beta)^{2}\left(W_{1}-W_{2}\right) \int_{-\infty}^{+\infty} f^{\prime} f d \varepsilon}{k}}}{2} .
$$

The following proposition studies the relationship between the optimal tax or subsidy rate and the degree of spillovers.

Proposition 3: When taxes or subsidies are chosen optimally in a symmetric equilibrium, $\frac{d t}{d \beta}<0$ if and only if $f_{U}<f_{L} ; \frac{d t}{d \beta}=0$ if and only if $f_{U}=f_{L} ; \frac{d t}{d \beta}>0$ if and only if $f_{U}>f_{L}$.

Proof: Differentiation of (15) with respect to $\beta$ yields

$$
\frac{d t}{d \beta}=\frac{2(1-\beta)\left(W_{1}-W_{2}\right) \int_{-\infty}^{+\infty} f^{\prime} f d \varepsilon}{\sqrt{k^{2}-4(1-\beta) k\left(W_{1}-W_{2}\right) \int_{-\infty}^{+\infty} f^{\prime} f d \varepsilon}}
$$

From (16), the sign of $d t^{\prime} d \beta$ is the same as the sign of $\int_{-\infty}^{+\infty} f^{\prime} f d \varepsilon_{j}$, which equals $\frac{1}{2}\left(f_{U}^{2}-f_{L}^{2}\right)$.

Q.E.D.

The intuition behind Proposition 3 is the following. From Proposition 2, there are three cases. First, when $f_{U}<f_{L}$, the domestic government wants to discourage the domestic firm to spend on R\&D. A higher spillover rate decreases a firm's incentive to spend on R\&D. As a result, the tax rate decreases with the degree of spillovers as the need to discourage a firm's incentive to spend on R\&D decreases. Second, when $f_{U}=f_{L}$, the optimal policy for the domestic government is laissezfaire as there is no strategic benefit from intervention. No matter what is the degree of spillovers, $t_{i}=0$. As a result, $d t / d \beta=0$. Finally, when $f_{U}>f_{L}$, the domestic government wants to encourage the domestic firm to spend on R\&D. A higher spillover rate decreases a firm's incentive to spend on R\&D. To compensate the effect from spillovers, the subsidy rate increases with the degree of spillovers.

When a country begins to be integrated into the world economy, one policy issue is the international enforcement of intellectual property rights. This may affect the degree of spillovers. For industries with $f_{U}>f_{L}$, a government may want 
to enforce property rights stricter so that the degree of spillovers is smaller and the need for subsidy is lower. For industries with $f_{U}<f_{L}$, a government may want to enforce property rights looser so that the degree of spillovers is higher and the need for tax is lower (a higher tax may lead to other types of distortions not considered here).

When governments choose taxes or subsidies to maximize national welfare, the joint welfare of the domestic country and the foreign country usually is not maximized. To maximize the joint welfare, governments should tax firms so that there is no R\&D spending. The reason is that the rewards to the winner and loser are fixed and firms' R\&D spending only dissipates the rents.

\section{Endogenous Reward to the Winner}

In the above sections, the reward to the winner is exogenously given. In real world situations, reward to the winner may be a function of its R\&D output. In this section, international $R \& D$ competition when the reward to the winner is endogenously determined by $R \& D$ spending is studied.

The game has two stages. In the first stage, governments make policy announcements simultaneously. In the second stage, firms choose their R\&D spending simultaneously. If a firm's R\&D output is higher than the other one, its reward is its $R \& D$ output. Otherwise, its reward is zero. Thus, a higher R\&D spending will not only increase a firm's probability of winning, but also increase the reward to winning.

The domestic firm's expected profit is

$$
\Pi_{i}=\int_{-\infty}^{+\infty}\left(\mu_{i}+\beta \mu_{j}+\varepsilon_{i}\right) F\left[(1-\beta)\left(\mu_{i}-\mu_{j}\right)+\varepsilon_{i}\right] f\left(\varepsilon_{i}\right) d \varepsilon_{i}-\left(1-t_{i}\right) k \mu_{i}^{2} / 2
$$

The first order condition for the domestic firm's profit maximization is ${ }^{4}$

$$
\begin{aligned}
& \int_{-\infty}^{+\infty} F\left[(1-\beta)\left(\mu_{j}-\mu_{i}\right)+\varepsilon_{i}\right] f d \varepsilon_{i} \\
& +(1-\beta) \int_{-\infty}^{+\infty}\left(\mu_{i}+\beta \mu_{j}+\varepsilon_{i}\right) f\left[(1-\beta)\left(\mu_{i}-\mu_{j}\right)+\varepsilon_{i}\right] f\left(\varepsilon_{i}\right) d \varepsilon_{j}-\left(1-t_{i}\right) k \mu_{i}=0 .
\end{aligned}
$$

Define

\footnotetext{
${ }^{4}$ It is assumed that the second order condition for profit maximization is satisfied. For example, when $k=0.5$ and $f(\varepsilon)=1 / 6$ for $\varepsilon \in[-3,3]$, the second order condition is satisfied.
} 


$$
\begin{gathered}
D_{e} \equiv \int_{-\infty}^{+\infty}\left(\mu_{i}+\beta \mu_{j}+\varepsilon_{i}\right) f^{\prime}\left[(1-\beta)\left(\mu_{i}-\mu_{j}\right)+\varepsilon_{i}\right] f d \varepsilon_{i} \\
+\int_{-\infty}^{+\infty} f\left[(1-\beta)\left(\mu_{i}-\mu_{j}\right)+\varepsilon_{i}\right] f d \varepsilon .
\end{gathered}
$$

The sign of $D_{e}$ affects the slope of the reaction function. $D_{e}$ measures the change in the domestic firm's marginal profitability when the foreign firm increases its R\&D spending. As the reward to the winner increases with $R \& D$ spending, when a firm increases its R\&D spending, the marginal benefit to the firm contains two parts. First, it increases a firm's probability of winning. The change of this effect is measured by the first term on the right-hand side of (19). Second, the reward to the winner will also increase. The change of the second effect is measured by the second term on the right-hand side of (19).

From (19), it can be shown that

$$
\frac{\partial \mu_{j}}{\partial \mu_{i}}=\frac{\partial^{2} \Pi_{i} / \partial^{2} \mu_{i}}{(1-\beta)^{2} D_{e}}
$$

The foreign firm's expected profit is

$$
\int_{-\infty}^{+\infty}\left(\mu_{j}+\beta \mu_{i}+\varepsilon_{j}\right) F\left[(1-\beta)\left(\mu_{j}-\mu_{i}\right)+\varepsilon_{j}\right] f\left(\varepsilon_{j}\right) d \varepsilon_{j}-\left(1-t_{j}\right) k \mu_{j}^{2} / 2
$$

Its first order condition for profit maximization is

$$
\begin{aligned}
& \int_{-\infty}^{+\infty} F\left[(1-\beta)\left(\mu_{j}-\mu_{i}\right)+\varepsilon_{j}\right] f\left(\varepsilon_{j}\right) d \varepsilon_{j} \\
& +(1-\beta) \int_{-\infty}^{+\infty}\left(\mu_{j}+\beta \mu_{i}+\varepsilon_{j}\right) f\left[(1-\beta)\left(\mu_{j}-\mu_{i}\right)+\varepsilon_{j}\right] f\left(\varepsilon_{j}\right) d \varepsilon_{j}-\left(1-t_{j}\right) k \mu_{j}=0 .
\end{aligned}
$$

Total differentiation of the first order condition for the domestic firm and the foreign firm yields

$$
\begin{aligned}
& \frac{d \mu_{i}}{d t_{i}}=\frac{-k \mu_{i} \partial^{2} \Pi_{j} / \partial^{2} \mu_{j}}{\Delta_{e}}, \\
& \frac{d \mu_{j}}{d t_{i}}=\frac{-(1-\beta)^{2} k \mu_{i} D_{e}}{\Delta_{e}} .
\end{aligned}
$$

where $\Delta_{e}$ is the determinant of the $2 \times 2$ Jacobian matrix.

The domestic government will choose taxes or subsidies optimally to maximize 
domestic national welfare, which is

$$
\int_{-\infty}^{+\infty}\left(\mu_{i}+\beta \mu_{j}+\varepsilon_{i}\right) F\left[(1-\beta)\left(\mu_{i}-\mu_{j}\right)+\varepsilon_{i}\right] f\left(\varepsilon_{i}\right) d \varepsilon_{i}-k \mu_{i}^{2} / 2
$$

Taking first order condition with respect to $t_{i}$ yields

$$
\left[\left(1-t_{i}\right) k \mu_{i}-k \mu_{i}\right] \frac{d \mu_{i}}{d t_{i}}+\frac{\partial \Pi_{i}}{\partial \mu_{j}} \frac{d \mu_{j}}{d t_{i}}=0 .
$$

The above equation is equivalent to

$$
t_{i}=\frac{1}{k \mu_{i}} \frac{\partial \prod_{i}}{\partial \mu_{j}} \frac{d \mu_{j} / d t_{i}}{d \mu_{i} / d t_{i}}
$$

Plugging (21) into (23) yields

$$
t_{i}=\frac{1}{k \mu_{i}} \frac{\partial \Pi_{i}}{\partial \mu_{j}} \frac{D_{e}}{\left(-\partial^{2} \Pi_{j} / \partial^{2} \mu_{j}\right)} .
$$

How does the domestic firm's profit change with the foreign firm's R\&D spending? From (17), it can be shown that

$$
\begin{gathered}
\frac{\partial \Pi_{i}}{\partial \mu_{j}}=-(1-\beta) \int_{-\infty}^{+\infty}\left(\mu_{i}+\beta \mu_{j}+\varepsilon_{i}\right) f\left[(1-\beta)\left(\mu_{i}-\mu_{j}\right)+\varepsilon_{i}\right] f\left(\varepsilon_{i}\right) d \varepsilon_{i} \\
+\beta \int_{-\infty}^{+\infty} F\left[(1-\beta)\left(\mu_{i}-\mu_{j}\right)+\varepsilon_{i}\right] f\left(\varepsilon_{i}\right) d \varepsilon_{i} .
\end{gathered}
$$

The interpretation of (25) is the following. An increase in the foreign firm's R\&D spending has two effects on the domestic firm's expected profit. First, it decreases the domestic firm's probability of winning. This is the first term on the right-hand side of (25). Second, it increases the domestic firm's reward if the domestic firm wins as the reward to the winner is its R\&D output. This is the second term on the right side of (25). From (25), the sign of $\partial \prod_{i} / \partial \mu_{j}$ depends on the degree of spillovers. When $\beta$ is close to zero, the first term on the right-hand side of (25) is negative and the second term is close to zero. The first effect dominates the second one and an increase in foreign firm's R\&D spending decreases the domestic firm's expected profit. When $\beta$ is close to 1 , the first term on the right-hand side of (25) is close to zero and the second term is positive. The second effect dominates and an increase in the foreign firm's R\&D spending will increase domestic firm's expected profit. 
The following proposition studies optimal R\&D policy when the reward to the winner is endogenously determined by $R \& D$ spending. It shows that optimal policy is not only sensitive to the type of uncertainty, but also sensitive to the degree of spillovers.

Proposition 4. For $\partial \Pi_{i} / \partial \mu_{j}<0$, the optimal policy for the domestic government is to tax the domestic firm when $D_{e}<0$; the optimal policy for the domestic government is laissez-faire when $D_{e}=0$; the optimal policy for the domestic government is to subsidize the domestic firm when $D_{e}>0$.

For $\partial \Pi_{i} / \partial \mu_{j}>0$, the optimal policy for the domestic government is to subsidize the domestic firm when $D_{e}<0$; the optimal policy for the domestic government is laissez-faire when $D_{e}=0$; the optimal policy for the domestic government is to tax the domestic firm when $D_{e}>0$.

Proof: From the second order condition for the foreign firm's profit maximization, $\partial^{2} \Pi_{j} / \partial^{2} \mu_{j}<0$. From (24), the sign of $t$ depends on both the sign of $\partial \Pi_{i} / \partial \mu_{j}$ and $D_{e}$.

Q.E.D.

The intuition behind Proposition 4 is the following. In general, optimal policy depends on both whether a higher R\&D spending makes the domestic firm "tough" or "soft" and the slope of the reaction function. ${ }^{5}$ For $\partial \Pi_{i} / \partial \mu_{j}<0$, a higher R\&D spending makes the domestic firm tough. From (20), the slope of the reaction curve depends on the sign of $D_{e}$. There are three situations. First, when $D_{e}$ is positive, the reaction curve has a negative slope and the domestic government's optimal policy is to subsidize the domestic firm. Second, when $D_{e}$ is equal to zero, the reaction curve has a slope of zero and the optimal policy is laissez-faire. Finally, when $D_{e}$ is negative, the reaction curve has a positive slope and the domestic government's optimal policy is to tax the domestic firm. For $\partial \Pi_{i} / \partial \mu_{j}>0$, higher R\&D spending makes the domestic firm soft and optimal policy is reversed. For $\partial \Pi_{i} / \partial \mu_{j}<0$, in the special case that random variables are uniformly distributed, Proposition 4 shows that the domestic government has an incentive to subsidize the domestic firm.

What is the impact of domestic government's intervention on the foreign firm's expected profit when the reward to the winner is endogenously determined by R\&D spending? From $\frac{d \Pi_{j}}{d t_{i}}=\frac{d \Pi_{j}}{d \mu_{i}} \frac{d \mu_{i}}{d t_{i}}$, the sign of $d \Pi_{j} / d t_{t}$ depends on the spillover rate.

\footnotetext{
${ }^{5}$ See Fudenberg and Tirole (1984) for additional illustration.
} 
When $\beta$ is small, $d \Pi_{j} / d \mu_{i}<0$ and $d \Pi_{j} / d t_{i}<0$. When the degree of spillovers is large, $d \Pi_{j} / d \mu_{i}>0$ and $d \Pi_{j} / d t_{i}>0$. Depending on the degree of spillovers and whether the domestic government subsidizes or taxes the domestic firm, there are four cases. First, when degree of spillovers is small and the domestic government taxes the domestic firm, the foreign firm's expected profit increases. Second, when degree of spillovers is small and the domestic government subsidizes the domestic firm, the foreign firm's expected profit decreases. Third, when degree of spillovers is large and the domestic government taxes the domestic firm, the foreign firm's expected profit decreases. Finally, when degree of spillovers is large and the domestic government subsidizes the domestic firm, the foreign firm's expected profit increases.

In the above sections, it is assumed that there is no domestic consumption of the new product. When there is domestic consumption of this good, domestic government may have an incentive to provide output subsidy to the domestic firm as firms ignore consumer surplus when making their output choices.

In the above sections, there are only one domestic firm and one foreign firm. Compared to the situation when there is only one domestic firm, having more than one domestic firms generates one additional effect. Now there are negative externalities among domestic firms as increasing R\&D spending by one domestic firm will decrease other domestic firms' probability of winning. Depending on the slope of the reaction function, there are three cases. First, when the reaction function has a negative slope, the domestic government wants to encourage the domestic firm to spend on R\&D when there is only one domestic firm. With the existence of the negative externality, the incentive to subsidize the domestic firm is smaller when there are multiple firms. Second, when the reaction function has a slope of zero, though there is no strategic benefit from intervention, the domestic government will tax domestic firms because of the existence of the negative externality. Finally, when there is only one domestic firm and the reaction function has a positive slope, the domestic government wants to discourage the domestic firm to spend on R\&D. This incentive works in the same direction as the negative externality when there are multiple firms. As a result, the domestic government will tax domestic firms.

For a country in autarky, when there are several firms conducting R\&D in this country, the domestic government may be strict in enforcing antitrust policies to prevent collusion among these firms. When this country begins to be integrated into the world economy and there are some firms in the foreign country conducting 
$\mathrm{R} \& \mathrm{D}$, it may be more desirable for the domestic government to allow domestic firms to cooperate in $R \& D$. One famous example of $R \& D$ cooperation is the Microelectronics and Computer Technology Corporation (MCC) in the US. MCC is a private venture with more than 20 participating firms. As Peck (1986) shows, the threat from Japanese firms and large domestic firms was a major reason for the formation of MCC. With foreign R\&D competition, the formation of MCC was not challenged by the US antitrust authorities.

\section{Conclusion}

This paper provides a unified approach to study the influence of uncertainty and spillovers on international R\&D competition. When the reward to the winner of competition is exogenously given, we show that domestic government's optimal $R \& D$ policy depends on the type of uncertainty that characterizes the $R \& D$ process. The size of tax or subsidy depends on the degree of spillovers. When the reward to the winner is endogenously determined by R\&D spending, the direction of optimal policy is not only sensitive to the type of uncertainty, but also sensitive to the degree of spillovers. In reality, a government may have limited information about the type of uncertainties faced by industries. Industries also differ in their degree of R\&D spillovers. Those factors will limit a government's ability to take an active role in helping its firms in R\&D competition.

\section{Acknowledgments}

I thank John A. List, Deborah Minehart, Yingyi Qian, Robert Schwab, and Daniel Vincent for their valuable comments. I also thank seminar participants at the Ryerson University and an anonymous referee for their useful suggestions.

Received 7 May 2006, Accepted 20 October 2006

\section{References}

Bagwell, K., and Staiger, R. W. (1992) The Sensitivity of Strategic and Corrective R\&D Policy in Battles for Monopoly, International Economic Review, 33, 795-816

Bagwell, K., and Staiger, R. W. (1994) The Sensitivity of Strategic and Corrective R\&D Policy in Oligopolistic Industries, Journal of International Economics, 36, 133-150 Brander, J. (1995) Strategic Trade Theory, in G. Grossman and K. Rogoff, eds., Handbook 
of International Economics, Volume 3, Amsterdam: North-Holland.

Bulow, J., Geanakoplos, J. and Klemperer, P. (1985) Multimarket Oligopoly: Strategic Substitutes and Complements, Journal of Political Economy, 93, 488-511

Coe, D., and Helpman, E. (1995) International R\&D Spillovers, European Economic Review, 39, 859-887

d'Aspremont, C., and Jacquemin, A. (1988) Cooperative and Noncooperative R\&D in Duopoly with Spillovers, American Economic Review, 78, 1133-1137

DeCourcy, J. (2005) Cooperative R\&D and Strategic Trade Theory, Canadian Journal of Economics, 38, 546-573

Fudenberg, D. and Tirole, J. (1984) The Fat-cat Effect, the Puppy-dog Ploy, and the Lean and Hungry Look, American Economic Review Papers and Proceedings, 74, 361-366

Keller, W. (2004) International Technology Diffusion, Journal of Economic Literature, 42, 752-782

Konrad, K. A. (2000) Trade Contests, Journal of International Economics, 51, 317-334

Lazear, E., and Rosen, S. (1981) Rank-order Tournaments as Optimum Labor Contracts, Journal of Political Economy, 89, 841-864

Leahy, D., and Neary, J. P. (1999) R\&D Spillovers and the Case for Industrial Policy in an Open Economy, Oxford Economic Papers, 51, 40-59

Levin, R., and Reiss, P. (1988) Cost-reducing and Demand-creating R\&D with Spillovers, RAND Journal of Economics, 19, 538-556

Miyagiwa, K., and Ohno, Y. (1997) Strategic R\&D Policy and Appropriability, Journal of International Economics, 42, 125-148

Muniagurria, M., and Singh, N. (1997) Foreign Technology, Spillovers, and R\&D policy, International Economic Review, 38, 405-430

Park, J. (2004) International and Intersectoral R\&D Spillovers in the OECD and East Asian Economies, Economic Inquiry, 42, 739-757

Peck, M. (1986) Joint R\&D: The Case of Microelectronics and Computer Technology Corporation, Research Policy, 15, 219-231

Spencer, B., Brander, J. A. (1983) International R\&D Rivalry and Industrial Strategy, Review of Economic Studies, 50, 707-722

The Washington Post (1992) A New Cold War Aims to Produce a Finer Fridge: Utilities Offer \$30 Million Prize for Energy, Environmental Gains, December 20, 1992, H1, H5.

Zhou, H. (2006) R\&D Tournaments with Spillovers, Atlantic Economic Journal, 34, 327-339 